\title{
Quantitative bone SPECT/CT: high specificity for identification of prostate cancer bone metastases
}

\author{
Flavian Tabotta ${ }^{\dagger}$, Mario Jreige ${ }^{\dagger}$, Niklaus Schaefer, Fabio Becce, John O. Prior and Marie Nicod Lalonde ${ }^{*}$ (ID
}

\begin{abstract}
Purpose: Bone scintigraphy with ${ }^{99 \mathrm{~m}} \mathrm{Tc}$-labeled diphosphonates can identify prostate cancer bone metastases with high sensitivity, but relatively low specificity, because benign conditions such as osteoarthritis can also trigger osteoblastic reactions. We aimed to investigate the diagnostic performance of ${ }^{99 \mathrm{~m}} \mathrm{Tc}-2,3$-dicarboxy propane1,1-diphosphonate $\left({ }^{99 \mathrm{~m}} \mathrm{Tc}\right.$-DPD) uptake quantification by single-photon emission computed tomography coupled with computed tomography (SPECT/CT) for distinguishing prostate cancer bone metastases from spinal and pelvic osteoarthritic lesions.

Methods: We retrospectively assessed 26 bone scans from 26 patients with known prostate cancer bone metastases and 13 control patients with benign spinal and pelvic osteoarthritic changes without known neoplastic disease. Quantitative SPECT/CT (xSPECT, Siemens Symbia Intevo, Erlangen, Germany) was performed and standardized uptake values (SUVs) were quantified with measurements of $S U V_{\max }$ and $S U V_{\text {mean }}(\mathrm{g} / \mathrm{mL})$ in all bone metastases for the prostate cancer group and in spinal and pelvic osteoarthritic changes for the control group. We used receiver operating characteristics (ROC) curves to determine the optimum SUV $V_{\max }$ Cutoff value to distinguish between bone metastases and benign spinal and pelvic lesions.
\end{abstract}

Results: In total, 264 prostate cancer bone metastases were analyzed, showing a mean SUV max and SUV mean of $34.6 \pm$ 24.6 and $20.8 \pm 14.7 \mathrm{~g} / \mathrm{mL}$, respectively. In 24 spinal and pelvic osteoarthritic lesions, mean SUV max and SUV mean were $14.2 \pm 3.8$ and $8.9 \pm 2.2 \mathrm{~g} / \mathrm{mL}$, respectively. SUV $\max$ and $S U V_{\text {mean }}$ were both significantly different between the bone metastases and osteoarthritic groups ( $p \leq 0.0001$ ). Using a $S U V_{\max }$ Cutoff of $19.5 \mathrm{~g} / \mathrm{mL}$ for prostate cancer bone metastases in the spine and pelvis, sensitivity, specificity, positive and negative predictive values were 87, 92,99 and $49 \%$, respectively.

Conclusion: This study showed significant differences in quantitative ${ }^{99 \mathrm{~m}} \mathrm{TC}-\mathrm{DPD}$ uptake on bone SPECT/CT between prostate cancer bone metastases and spinal and pelvic osteoarthritic changes, with higher SUV max and $S U V_{\text {mean }}$ in metastases. Using a SUV $\max$ Cutoff of $19.5 \mathrm{~g} / \mathrm{mL}$, high specificity and positive predictive value for metastases identification in the spine and pelvis were found, thus increasing accuracy of bone scintigraphy.

Keywords: SPECT/CT, SUV, Bone metastases, Prostate cancer, Bone scintigraphy, Spinal osteoarthritis, ${ }^{99 m}$ Tc-DPD, XSPECT, Quantitative SPECT, Prostate cancer metastases

\footnotetext{
* Correspondence: Marie.Nicod-Lalonde@chuv.ch

†Flavian Tabotta and Mario Jreige contributed equally to this work.

Lausanne University Hospital and University of Lausanne, Rue du Bugnon 46,

1011 Lausanne, Switzerland
}

(c) The Author(s). 2019 Open Access This article is distributed under the terms of the Creative Commons Attribution 4.0 International License (http://creativecommons.org/licenses/by/4.0/), which permits unrestricted use, distribution, and reproduction in any medium, provided you give appropriate credit to the original author(s) and the source, provide a link to the Creative Commons license, and indicate if changes were made. The Creative Commons Public Domain Dedication waiver (http://creativecommons.org/publicdomain/zero/1.0/) applies to the data made available in this article, unless otherwise stated. 


\section{Introduction}

In developed countries, prostate cancer is the most frequently diagnosed cancer among men and the fifth leading cause of cancer death [1]. Bone is the main site of distant metastases [2], with a high yet underreported prevalence [3]. Standard initial local treatment options include watchful waiting, radiation therapy and radical prostatectomy. Recurrence is detected by serum elevation of prostate specific antigen (PSA). Accurate initial staging and restaging, namely the detection of bone metastases, is essential for choosing the most appropriate treatment for the patient.

${ }^{99} \mathrm{~m}$ Tc-diphosphonates bone scintigraphy is the most widely available imaging modality worldwide to detect bone metastases in patients with prostate cancer. Bone scintigraphy uses DPD-labelled with ${ }^{99 \mathrm{~m}} \mathrm{Tc}$, which accumulate in remodeling bone by incorporation into the crystalline structure of calcium hydroxyapatite [3]. ${ }^{99 m}$ Tc-DPD bone uptake depends on bone osteoblastic activity, vascularization and environmental factors. Bone metastases of prostate cancer trigger an important osteoblastic reaction and substantially accumulate ${ }^{99} \mathrm{~m}$ Tc-DPD. Planar bone scintigraphy has a high sensitivity but a relatively low specificity for characterizing bone metastases in prostate cancer patients. Indeed, benign conditions, such as degenerative joint and disk diseases, also trigger an increase in bone turnover and radiotracer accumulation. The $3 \mathrm{D}$ data acquired during bone scintigraphy, named single-photon emission computed tomography (SPECT), can be coupled with computed tomography (CT), a morphological imaging modality. It is well known that combined SPECT/CT increases the specificity of bone scintigraphy as the sites of increased ${ }^{99 \mathrm{~m}} \mathrm{Tc}$-DPD uptake can be correlated to morphological changes on CT images [4-6].

Recently, technological advances have allowed ${ }^{99 \mathrm{~m}} \mathrm{Tc}$ DPD uptake quantification (xSPECT/CT, Siemens Symbia Intevo). xSPECT has an accurate activity recovery within $10 \%$ of the expected value for objects $>10$ $\mathrm{mL}$, which is similar to PET/CT [7]. The aim of this study was to investigate the diagnostic performance of ${ }^{99 \mathrm{~m}}$ Tc-DPD uptake quantification for distinguishing bone metastases from benign spinal and pelvic osteoarthritic lesions in prostate cancer patients.

\section{Materials and methods}

\section{Patient selection}

We retrospectively analyzed 26 bone scans from 26 male patients (mean age $74 \pm 10$ years; range $55-92$ years) with confirmed prostate cancer on biopsy or based on biological data and imaging follow-up, referred for evaluation of bone metastases between January 2016 and December 2018. The second group consisted of 13 male patients (70 \pm 15 years; range $32-83$ years) without any known neoplastic disease, referred for investigation of various benign musculoskeletal disorders. Patient data, including body mass index (BMI), administered ${ }^{99 \mathrm{~m}} \mathrm{Tc}$ DPD activity, creatinine levels, PSA levels and time interval between radiotracer injection and image acquisition were retrieved.

\section{SPECT/CT image analysis}

All patients underwent whole-body planar imaging with the low-energy high-resolution collimator with a scanning speed of $12 \mathrm{~cm} / \mathrm{min}$ and quantitative xSPECT/CT (Siemens Symbia Intevo, Erlangen, Germany) on regions with high uptake on planar scintigraphy. The xSPECT was acquired in average at $3 \mathrm{~h} 35 \pm 54 \mathrm{~min}$ in the bone metastases group and $3 \mathrm{~h} 50 \pm 50 \mathrm{~min}$ in the osteoarthritic group, after intravenous injection of $10 \mathrm{MBq} / \mathrm{kg}$ of ${ }^{99 m}$ Tc-DPD (this radiotracer has been in use in our center for over 2 decades, as we believe the bone/soft tissue ratio is better) with a mean patient dose of $777 \pm 113$ $\mathrm{MBq}$ and $733 \pm 101 \mathrm{MBq}$, respectively. Images were acquired with 3 degrees rotation/step and $12 \mathrm{~s} /$ projection with a $256 \times 256$ matrix. Reduced dose CT was acquired with $130 \mathrm{kV}$ and 25 reference mAs modulation (Siemens Care Dose, Symbia Intevo, Erlangen, Germany). Images were reconstructed to generate SPECT data allowing $\mathrm{SUV}_{\mathrm{bw}}$ quantification on post-processed images and measurement of $\mathrm{SUV}_{\max }$ and $\mathrm{SUV}_{\text {mean }}(\mathrm{g} / \mathrm{mL})$ using xSPECT reconstruction algorithm.

For each patient in the bone metastases group, SUVmax and $\mathrm{SUV}_{\text {mean }}$ of all prostate cancer bone metastases visible on SPECT and CT were measured (Fig. 1a). For each patient in the control group, $\mathrm{SUV}_{\max }$ and $\mathrm{SUV}_{\text {mean }}$ were measured in the active degenerative changes of the lumbar spine and pelvis on SPECT/CT (Fig. 1b). For all patients, the $\mathrm{SUV}_{\text {mean }}$ of lumbar vertebrae was measured in a 4 to $5 \mathrm{~cm}^{3}$ region of interest (ROI), with no metastatic or osteoarthritic lesion visible on SPECT and CT.

\section{Statistical analysis}

Statistical differences between bone metastases and osteoarthritic groups regarding age, BMI, creatinine levels, lumbar vertebrae $\mathrm{SUV}_{\max }$ and $\mathrm{SUV}_{\text {mean }}$, time interval between radiotracer injection and image acquisition, were calculated using the Wilcoxon rank-sum test. Mean values, standard deviations (SD) of $\mathrm{SUV}_{\max }$ and $\mathrm{SUV}_{\text {mean }}$ in both metastatic and osteoarthritic groups were calculated and statistical differences assessed by the Wilcoxon rank-sum test. Subgroup analysis taking into account the metastases location was performed in the bone metastases group. Differences in SUV $\max$ and SUVmean between subgroups were assessed using one-way ANOVA. We also used receiver operating characteristics (ROC) curves to determine the best-fit cutoff values of $\mathrm{SUV}_{\text {max }}$ between metastatic and osteoarthritic lesions, 

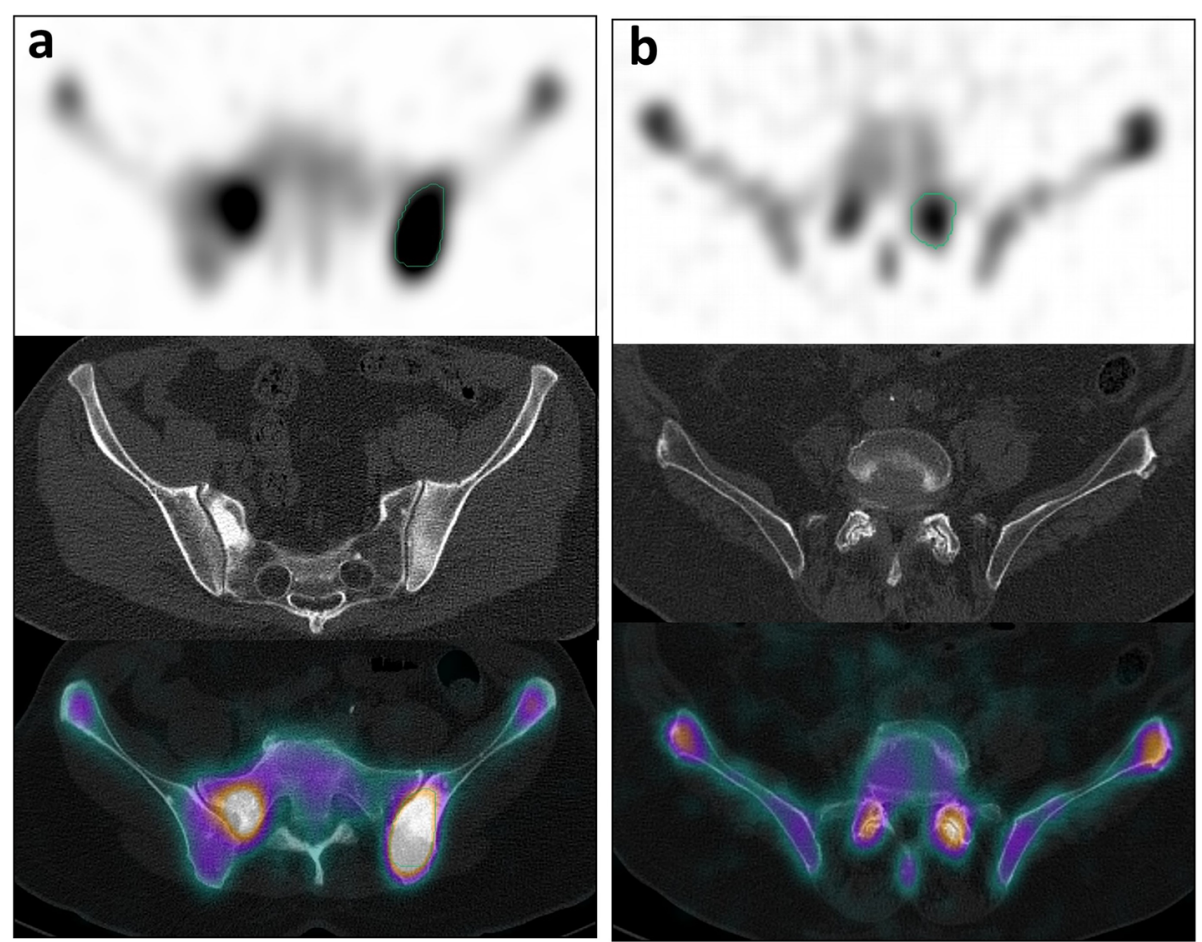

Fig. 1 a Osteoblastic lesion of the pelvis in a 57-year-old male patient known for prostate cancer, showing a high SUV $\max$ of $28 \mathrm{~g} / \mathrm{mL}$ and SUV mean of $17 \mathrm{~g} / \mathrm{mL}$. $\mathbf{b}$ Lumbar spine osteoarthritic changes of the L4-L5 facet joints in a 83-year-old male patient with hip pain, showing SUV $V_{\text {max }}$ of 15 and $13 \mathrm{~g} / \mathrm{mL}$ and $S U V_{\text {mean }}$ of 9.0 and $7.8 \mathrm{~g} / \mathrm{mL}$ in the left and right facet joints, respectively

with computation of the respective sensitivity, specificity, positive and negative predictive values. All statistical analyses were performed using STATA (version 15.1; STATA Corp., College Station, Texas, USA). P-values less than 0.05 were considered as statistically significant.

\section{Results}

There were no significant differences between the bone metastases and osteoarthritic groups regarding age, BMI, creatinine levels, time between radiotracer injection and $\mathrm{xSPECT}$ imaging and lumbar vertebrae $\mathrm{SUV}_{\max }$ and $\mathrm{SUV}_{\text {mean }}$ (Table 1). The average lumbar vertebrae SUVmax and $\mathrm{SUV}_{\text {mean }}$ of all patients were $8.8 \pm 2.3$ and $6.9 \pm$ $1.9 \mathrm{~g} / \mathrm{mL}$, respectively. The PSA level in the metastatic group was $206 \pm 573 \mu \mathrm{g} / \mathrm{L}$.

A total number of 265 prostate cancer bone metastases (221 osteoblastic, 5 osteolytic, 35 mixed and 4 nonclassified) were analyzed, showing a mean $\mathrm{SUV}_{\max }$ and $\mathrm{SUV}_{\text {mean }}$ of $35 \pm 25$ and $21 \pm 15 \mathrm{~g} / \mathrm{mL}$, respectively. In the osteoarthritic group, 24 active focal osteoarthritic changes (20 spinal and 4 pelvic) were analyzed and showed a mean $\mathrm{SUV}_{\text {max }}$ and $\mathrm{SUV}_{\text {mean }}$ of $14.2 \pm 3.8$ and $8.9 \pm 2.2 \mathrm{~g} / \mathrm{mL}$, respectively. $\mathrm{SUV}_{\max }$ and $\mathrm{SUV}_{\text {mean }}$ were both significantly different between bone metastatic and osteoarthritic lesions $(p<0.0001)$ (Fig. 2a).

In the bone metastases group, there were 87 lesions in the pelvis $\left(\mathrm{SUV}_{\max } 44 \pm 25 \mathrm{~g} / \mathrm{mL}\right.$ and $\mathrm{SUV}_{\text {mean }} 26 \pm 15 \mathrm{~g} /$
$\mathrm{mL}), 84$ lesions in the spine $\left(\mathrm{SUV}_{\max } 39 \pm 28 \mathrm{~g} / \mathrm{mL}\right.$ and $\mathrm{SUV}_{\text {mean }} 24 \pm 17 \mathrm{~g} / \mathrm{mL}$ ), 28 lesions in the scapular girdle $\left(\mathrm{SUV}_{\max } 27 \pm 12 \mathrm{~g} / \mathrm{mL}\right.$ and $\left.\mathrm{SUV}_{\text {mean }} 16 \pm 7.2 \mathrm{~g} / \mathrm{mL}\right), 54$ lesions in the ribs $\left(\mathrm{SUV}_{\max } 18 \pm 8.9 \mathrm{~g} / \mathrm{mL}\right.$ and $\mathrm{SUV}_{\text {mean }}$ $10.6 \pm 5.1 \mathrm{~g} / \mathrm{mL}$ ), and 12 lesions in the extremities (SUV$\max 33 \pm 26 \mathrm{~g} / \mathrm{mL}$ and $\mathrm{SUV}_{\text {mean }} 20 \pm 16 \mathrm{~g} / \mathrm{mL}$ ). $\mathrm{SUV}_{\max }$ and $\mathrm{SUV}_{\text {mean }}$ of metastatic lesions in the spine and pelvis were significantly higher than in osteoarthritic lesions $(p<0.0001)$, whereas there was no significant difference between SUVs of osteoarthritic changes and metastatic

Table 1 Patient characteristics in the prostate cancer bone metastases and spinal and pelvic osteoarthritis groups

\begin{tabular}{llll}
\hline & $\begin{array}{l}\text { Bone Metastases } \\
\text { Group } \\
(n=26)\end{array}$ & $\begin{array}{l}\text { Osteoarthritis } \\
\text { Group } \\
(n=13)\end{array}$ & $P$-value \\
\hline Age (years) & $74 \pm 10$ & $70 \pm 15$ & 0.68 \\
BMI (kg/m $\left.{ }^{2}\right)$ & $25.6 \pm 4.9$ & $25 \pm 3.2$ & 0.87 \\
$\begin{array}{l}\text { Creatinine level } \\
(\mu \text { mol/L) }\end{array}$ & $92.3 \pm 27.4$ & $96.1 \pm 33.3$ & 0.66 \\
$\begin{array}{l}\text { Time interval between } \\
\text { injection and xSPECT } \\
\text { imaging (min) }\end{array}$ & $215 \pm 54$ & $230 \pm 50$ & 0.32 \\
$\begin{array}{l}\text { SUV } \\
\text { vertebrae }\end{array}$ & & & \\
$\begin{array}{l}\text { SUV } \\
\text { vertebrax lumbar }\end{array}$ & $6.7 \pm 1.9$ & $7.3 \pm 1.9$ & 0.26 \\
\hline
\end{tabular}



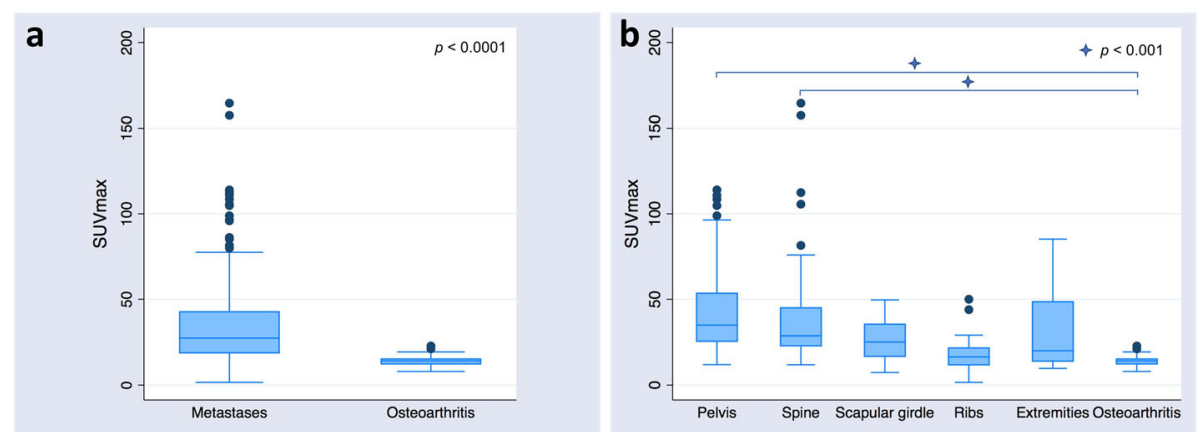

Fig. 2 Box-and-whisker plots of SUV $\max$ overall (a) and depending on metastases location (b)

lesions in the ribs, scapular girdle, and the extremities ( $p=0.53, p=1.0$ and $p=0.3$, respectively) (Fig. 2b).

In the bone metastases group, 16 patients had previous therapy before relapse. All 16 patients had hormone therapy, one patient had Xofigo ( ${ }^{223}$ Radium dichloride) and immunotherapy prior to bone scan and another patient had chemotherapy. $\mathrm{SUV}_{\max }$ and $\mathrm{SUV}_{\text {mean }}$ of the bone metastases were not significantly lower in patients having had previous systemic therapy compared to patients without previous treatment $\left(\mathrm{SUV}_{\max } 32 \pm 22\right.$ versus $40 \pm 29 \mathrm{~g} / \mathrm{mL}, p=0.18$, and $\mathrm{SUV}_{\text {mean }} 20 \pm 14$ versus $23 \pm 17 \mathrm{~g} / \mathrm{mL}, p=0.3$ ) (Fig. 3a). Interestingly, this difference became significant when only spinal and pelvic bone metastases were considered: $\mathrm{SUV}_{\max } 37 \pm 24$ versus $50 \pm 30 \mathrm{~g} / \mathrm{mL}(p=0.01)$ and $\mathrm{SUV}_{\text {mean }} 23 \pm 14$ versus $30 \pm$ $18 \mathrm{~g} / \mathrm{mL}(p=0.03)$, respectively (Fig. 3b).

ROC curves showed that both $\mathrm{SUV}_{\max }$ and $\mathrm{SUV}_{\text {mean }}$ had very good diagnostic accuracy for differentiating between spinal and pelvic bone metastases and osteoarthritic changes (AUC 0.947 and 0.943 , respectively) (Fig. 4). The optimum cutoff value of $\mathrm{SUV}_{\max }$ for defining spinal and pelvic prostate cancer bone metastases was $19.5 \mathrm{~g} / \mathrm{mL}$. Using this cutoff value, we found a sensitivity, specificity, positive and negative predictive values of $87 \%$ [95\% CI: $81-91 \%$ ], 92\% [73-99\%], 99\% [95-100\%] and 49\% [34-64\%], respectively. This cutoff value remained identical even in patients who had prior therapy, with a sensitivity, specificity, positive and negative predictive values of $86 \%$ [95\% CI: $78-91 \%$ ], $92 \%$ [73-99\%], 98\% [93-100\%] and 56\% [40-72\%], respectively.

\section{Discussion}

In this study, we showed that quantification in bone scintigraphy could help in distinguishing prostate cancer bone metastases from spinal and pelvic osteoarthritic changes, and therefore increase bone scan specificity. Using an optimum SUV $_{\max }$ cutoff of $19.5 \mathrm{~g} / \mathrm{mL}$ for defining spinal and pelvic bone metastases on SPECT/CT, bone scan yielded a sensitivity, specificity, positive and negative predictive values of $87,92,99$ and $49 \%$, respectively.

To the best of our knowledge, only few studies previously reported on the quantification of ${ }^{99 \mathrm{~m}} \mathrm{Tc}-\mathrm{DPD}$
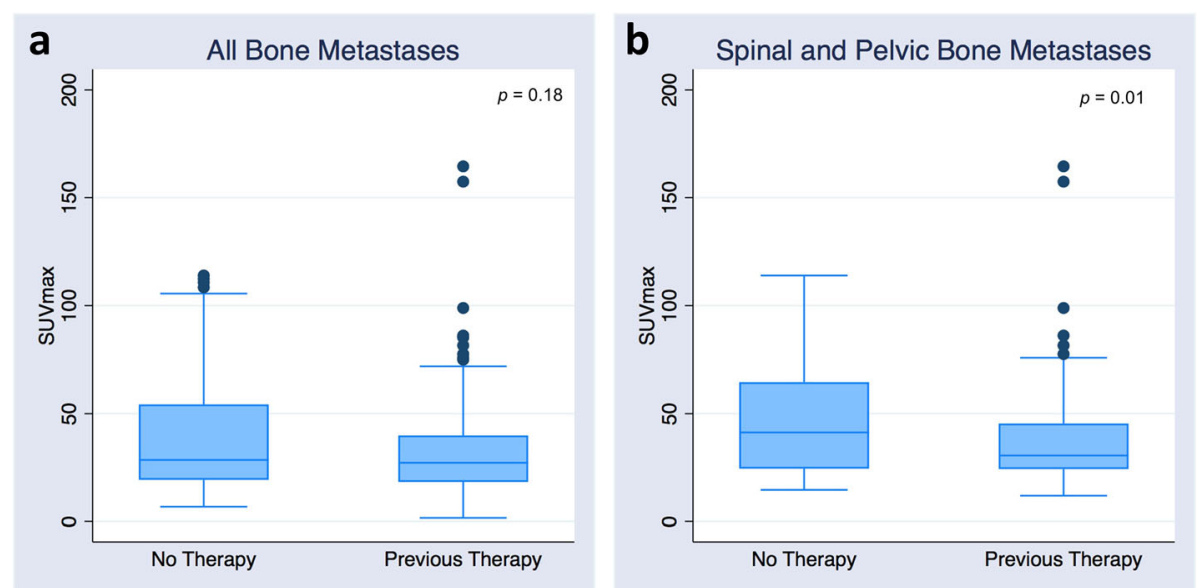

Fig. 3 Box-and-whisker plots of SUV $\max$ depending on presence or absence of previous systemic therapy in all bone metastases (a) and in spinal and pelvic bone metastases (b) 


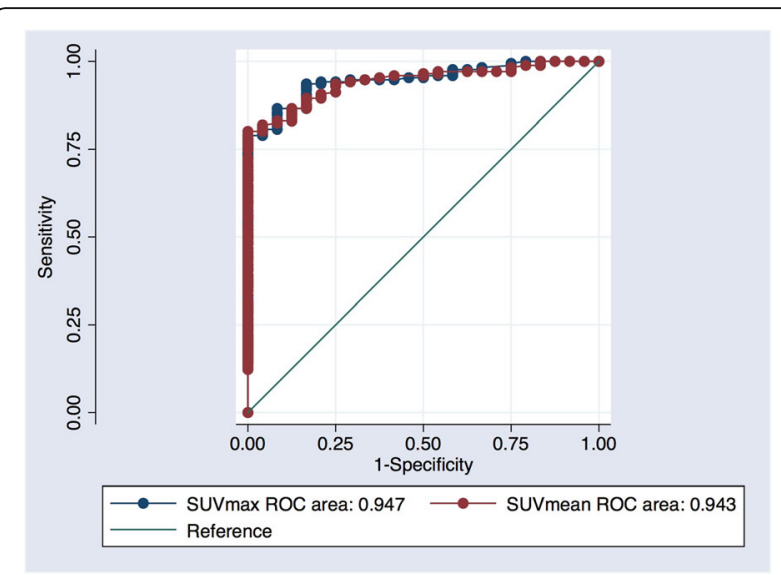

Fig. 4 ROC curves of SUV max and SUV mean for spinal and pelvic prostate cancer bone metastases, with AUCs of 0.947 and 0.943, respectively

uptake in bone metastases of prostate cancer patients. Beck et al. showed that the mean $S_{U V} V_{\text {peak }}$ of metastatic lesions in breast and prostate cancer patients was $20.4 \pm$ $20.8 \mathrm{~g} / \mathrm{mL}$ [8]. This difference is at least partly due to the fact that $\mathrm{SUV}_{\text {peak }}$ is usually lower than $\mathrm{SUV}_{\text {max }}$. Moreover, patients included in their study were both prostate and breast cancer patients combined, with a majority of the latter. Since breast cancer metastases are both osteoblastic and osteolytic, their uptake is probably lower than that of prostate cancer metastases, which are mostly osteoblastic as in our patient population. SUVs were further higher in our study than those reported by Umeda et al., who found a lower threshold of $7 \mathrm{~g} / \mathrm{mL}$ of $\mathrm{SUV}_{\max }$, above which the tumor burden of metastatic prostate cancer patients was determined [9]. Kuji et al. reported a high accuracy of quantitative SPECT/CT for the diagnosis of bone metastases in 170 prostate cancer patients [10]. They used a different reconstruction algorithm based on CT zonal mapping and included only the three hottest lesions explaining a slightly higher $\mathrm{SUV}_{\text {max }}$ and $\mathrm{SUV}_{\text {mean }}\left(\mathrm{SUV}_{\max }\right.$ of $35 \pm 25 \mathrm{~g} / \mathrm{mL}$ in our study versus $41 \pm 34 \mathrm{~g} / \mathrm{mL}$ in the study by Kuji et al., and a mean $S_{U V}$ mean of $21 \pm 15 \mathrm{~g} / \mathrm{mL}$ versus $24.6 \pm 21.2 \mathrm{~g} /$ $\mathrm{mL}$, respectively). We had similar quantitative results compared to Kuji et al. regarding radiotracer uptake by spinal osteoarthritic changes with a mean $\mathrm{SUV}_{\max }$ of $14.2 \pm 3.8 \mathrm{~g} / \mathrm{mL}$ compared to $16.7 \pm 6.7 \mathrm{~g} / \mathrm{mL}$, and a mean $\mathrm{SUV}_{\text {mean }}$ of $8.9 \pm 2.2 \mathrm{~g} / \mathrm{mL}$ compared to $9.5 \pm 3.9 \mathrm{~g} /$ $\mathrm{mL}$, respectively. Interestingly, SUVs were comparable although the radiotracers used for the bone scan were slightly different: ${ }^{99 \mathrm{~m}} \mathrm{Tc}$-DPD versus ${ }^{99 \mathrm{~m}} \mathrm{Tc}$-methylene diphosphonate $\left({ }^{99 \mathrm{~m}} \mathrm{Tc}-\mathrm{MDP}\right)$ in the Kuji et al. study. Thus, SUVs seem not only comparable from one center to another but also comparable regardless of which type of diphosphonate is used. This is further reinforced by comparable lumbar vertebrae $\mathrm{SUV}_{\text {mean }}$ in our study compared to the vertebral $\mathrm{SUV}_{\text {mean }}$ in the study by Cachovan et al. (SUV mean $6.9 \pm 1.9$ in our study versus $5.91 \pm 1.54$ in the Cachovan et al. study) [11].

In our study, $\mathrm{SUV}_{\max }$ and $\mathrm{SUV}_{\text {mean }}$ of metastatic lesions varied depending on the lesion location, with lowest values in the ribs and scapular girdle, which is similar to the observations from Beck and al [8]. This is probably at least partly due to the size of the lesions, which tend to be smaller in the ribs and scapular girdle with partial volume effect, as described for PET [12]. Different vascularization and osteoblastic reaction in these different anatomical regions may also play a role. There was no significant difference in $\mathrm{SUV}_{\max }$ and SUVmean between metastatic lesions in the ribs, scapular girdle and extremities, and osteoarthritic lesions; hence, no cutoff value could be obtained to distinguish between them. For lesions in the spine and pelvis, we found an optimum $\mathrm{SUV}_{\max }$ cutoff of $19.5 \mathrm{~g} / \mathrm{mL}$ with a very high sensitivity and positive predictive value. We believe this cutoff could be of added diagnostic value enabling physicians to decide with a high accuracy that a focal ${ }^{99 \mathrm{~m}} \mathrm{Tc}$ DPD uptake in the spine or pelvis above $19.5 \mathrm{~g} / \mathrm{mL}$ is most likely to be metastatic in a patient with known prostate cancer.

In this study, $\mathrm{SUV}_{\max }$ was significantly lower in spinal and pelvic bone metastases of patients relapsing after prior systemic therapy compared to patients with no previous systemic treatment. This is not surprising as previous treatment may induce sclerosis, reduced vascularization, or other tumor environment changes, which can all influence ${ }^{99 \mathrm{~m}} \mathrm{Tc}$-DPD uptake. Understanding the mechanism of reduced uptake in these lesions may help better understand the bone tumor microenvironment of prostate metastases [13]. Interestingly, the $\mathrm{SUV}_{\max }$ cutoff of $19.5 \mathrm{~g} / \mathrm{mL}$ still had a high positive predictive value for spinal and pelvic bone metastases in patients having received prior treatment for bone metastases.

There are of course other nuclear medicine modalities available for the detection and characterization of bone metastases in prostate cancer patients. ${ }^{68} \mathrm{Ga}$-prostate specific membrane antigen (PSMA), ${ }^{18} \mathrm{~F}$-choline and ${ }^{18} \mathrm{~F}$ sodium fluoride $(\mathrm{NaF})$ PET/CT all have very good accuracies for the diagnosis of prostate cancer bone metastases [14-17]. The most promising modality seems to be ${ }^{68} \mathrm{Ga}$-PSMA PET/CT $[18,19]$. Nonetheless, in many countries, ${ }^{68} \mathrm{Ga}$-PSMA, ${ }^{18} \mathrm{~F}$-Choline and ${ }^{18} \mathrm{~F}-\mathrm{NaF}$ PET are not widely available for primary staging due to cost and reimbursement issues, as impact on patient management and cost-effective studies are not yet available [20]. A study comparing PSA cutoff value for ordering ${ }^{18} \mathrm{~F}-\mathrm{NaF}$ PET or bone scintigraphy in patients with newly diagnosed prostate cancer showed no major difference between both modalities [20]. Furthermore, a 
recent study by Arvola et al. showed a strong correlation between SUVs from ${ }^{99 \mathrm{~m}} \mathrm{Tc}$-HDP SPECT/CT and ${ }^{18} \mathrm{~F}$ $\mathrm{NaF}$ PET/CT [21]. The authors concluded that SPECT is an applicable tool for clinical quantification of bone metabolism in osseous metastases in breast and prostate cancer patients.

Therefore, quantitative bone scintigraphy seems to increase bone SPECT/CT accuracy, allowing bone scintigraphy to remain competitive in the era of new multimodality imaging of bone metastases in prostate cancer patients. We believe that the $\mathrm{SUV}_{\max }$ cutoff of $19.5 \mathrm{mg} / \mathrm{L}$ for spinal and pelvic lesions could further increase bone scan specificity.

The main limitations of our study are the small subject population and the lack of histological confirmation for all prostate cancer bone metastases. However, as authors reported that histological confirmation may be avoided in the case of typical morphological imaging findings and patterns of radiotracer uptake [22], lesions were thus diagnosed as metastatic on conventional SPECT/CT and were subsequently analyzed for tracer uptake quantification. In addition, since we proceeded with a lesion-based analysis, the relatively small number of patients did not allow correlating further the level of uptake with the different histological grades of prostate cancer.

\section{Conclusion}

This study demonstrated significant differences in ${ }^{99 \mathrm{~m}} \mathrm{Tc}$-DPD uptake on bone scan between prostate cancer bone metastases and spinal and pelvic osteoarthritic changes based on quantitative data analysis, with significantly higher $\mathrm{SUV}_{\text {max }}$ and $\mathrm{SUV}_{\text {mean }}$ in metastases. Using an optimum $\mathrm{SUV}_{\max }$ cutoff of $19.5 \mathrm{~g} / \mathrm{mL}$ for defining spinal and pelvic bone metastases on SPECT/CT, bone scan yielded a sensitivity, specificity, positive and negative predictive values of $87,92,99$ and $49 \%$, respectively. Hence, adding quantitative data analysis to bone scan interpretation can help to characterize more confidently malignant versus benign spinal and pelvic focal bone lesions, and thus increase the overall diagnostic performance of bone scintigraphy. The main limitations of this study remain the small subject population and lack of histological confirmation of the metastatic lesions.

\section{Abbreviations \\ 95\%Cl: 95\% confidence interval; ${ }^{99 \mathrm{~m} T c-D P D:}{ }^{99 \mathrm{~m}} \mathrm{Tc}-2,3$-dicarboxy propane-1,1- diphosphonate; ${ }^{99 \mathrm{~m}} \mathrm{Tc}-\mathrm{MDP}:{ }^{99 \mathrm{~m}} \mathrm{Tc}-\mathrm{methylene}$ diphosphonate; NaF: Sodium fluoride; PSA: Prostate specific antigen; PSMA: Prostate specific membrane antigen; ROC: Receiver operating characteristics; SD: Standard deviation; SPECT/CT: Single-photon emission computed tomography coupled with computed tomography; SUV: Standardized uptake value; xSPECT: Quantitative xSPECT}

\section{Acknowledgments}

We thank Christine Geldhof for managing the ethical committee requirements and all nuclear medicine technologists involved in the patient data acquisitions.

\section{Declarations}

Compliance with Ethical Standards, Consent and Permissions.

\section{Authors' contributions}

MJ, MNL and JOP designed the study. FT and MJ analyzed the bone scans and retrieved the data. MJ, MNL and JOP performed the statistical analysis. MJ, FT and MNL drafted the manuscript. FB, JOP and NS critically revised the manuscript. All authors read and approved the final version of manuscript.

\section{Funding}

This study benefited from no funding.

\section{Availability of data and materials}

The datasets analyzed during the current study are available from the corresponding author on reasonable request.

\section{Ethics approval and consent to participate}

The procedure followed was in accordance with the ethical standards of the institutional research committee. The local Ethics Research Committee of the State of Vaud approved this research protocol (CER-VD \#2017-01492) and, considering the retrospective nature of the study, waived the need for obtaining patient informed consent. Patients who had refused to sign the general hospital informed consent form were excluded from the study. Patients who signed the general hospital informed consent or did not receive it were included in this retrospective study.

\section{Consent for publication}

Both patients whose images appear in the figures of this paper have signed the general hospital informed consent.

\section{Competing interests}

The authors declare that they have no conflict of interest.

Received: 6 August 2019 Accepted: 11 December 2019

Published online: 26 December 2019

References

1. Torre LA, et al. Global cancer statistics, 2012. CA Cancer J Clin. 2015;65(2): 87-108.

2. Lin SC, et al. Endothelial-to-osteoblast conversion generates osteoblastic metastasis of prostate cancer. Dev Cell. 2017:41(5):467-80 e3.

3. Kanishi D. $99 \mathrm{mTC}-\mathrm{MDP}$ accumulation mechanisms in bone. Oral Surg Oral Med Oral Pathol. 1993;75(2):239-46.

4. Helyar $V$, et al. The added value of multislice SPECT/CT in patients with equivocal bony metastasis from carcinoma of the prostate. Eur J Nucl Med Mol Imaging. 2010;37(4):706-13.

5. Strobel K, et al. Characterization of focal bone lesions in the axial skeleton: performance of planar bone scintigraphy compared with SPECT and SPECT fused with CT. AJR Am J Roentgenol. 2007;188(5):W467-74.

6. Saha S, et al. SPECT-CT: applications in musculoskeletal radiology. $\mathrm{Br} J$ Radiol. 2013;86(1031):20120519.

7. Gnesin S, et al. Phantom validation of Tc-99m absolute quantification in a SPECT/CT commercial device. Comput Math Methods Med. 2016;2016: 4360371.

8. Beck $M$, et al. Longitudinal analysis of bone metabolism using SPECT/CT and (99m)Tc-diphosphono-propanedicarboxylic acid: comparison of visual and quantitative analysis. EJNMMI Res. 2016;6(1):60.

9. Umeda $T$, et al. Evaluation of bone metastatic burden by bone SPECT/CT in metastatic prostate cancer patients: defining threshold value for total bone uptake and assessment in radium-223 treated patients. Ann Nucl Med. 2018; 32(2):105-13.

10. Kuji I, Yamane T, Seto A, Yasumizu Y, Shirotake S, Oyama M. Skeletal standardized uptake values obtained by quantitative SPECT/CT as an osteoblastic biomarker for the discrimination of active bone metastasis in prostate cancer. Eur J Hybrid Imag. 2017;1(1):2.

11. Cachovan M, et al. Quantification of $99 \mathrm{mTC}$-DPD concentration in the lumbar spine with SPECT/CT. EJNMMI Res. 2013;3(1):45.

12. van der Vos CS, et al. Quantification, improvement, and harmonization of small lesion detection with state-of-the-art PET. Eur J Nucl Med Mol Imaging. 2017:44(Suppl 1):4-16. 
13. Wong SK, et al. Prostate cancer and bone metastases: the underlying mechanisms. Int J Mol Sci. 2019;20(10):2587.

14. Pyka T, et al. Comparison of bone scintigraphy and (68) Ga-PSMA PET for skeletal staging in prostate cancer. Eur J Nucl Med Mol Imaging. 2016; 43(12):2114-21.

15. Garcia JR, et al. Diagnostic performance of bone scintigraphy and (11) C choline PET/CT in the detection of bone metastases in patients with biochemical recurrence of prostate cancer. Rev Esp Med Nucl Imagen Mol. 2015;34(3):155-61.

16. Even-Sapir $\mathrm{E}$, et al. The detection of bone metastases in patients with highrisk prostate cancer: $99 \mathrm{mTc}-\mathrm{MDP}$ planar bone scintigraphy, single- and multi-field-of-view SPECT, 18F-fluoride PET, and 18F-fluoride PET/CT. J Nucl Med. 2006;47(2):287-97.

17. Beheshti $\mathrm{M}$, et al. Evaluation of prostate cancer bone metastases with $18 \mathrm{~F}$ NaF and 18F-Fluorocholine PET/CT. J Nucl Med. 2016:57(Suppl 3):55S-60S.

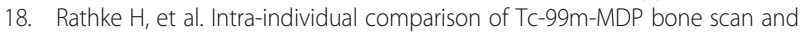
the PSMA-ligand Tc-99m-MIP-1427 in patients with osseous metastasized prostate cancer. J Nucl Med. 2018;59:1373-79.

19. Zacho HD, et al. (68) Ga-PSMA PET/CT for the detection of bone metastases in prostate cancer: a systematic review of the published literature. Clin Physiol Funct Imaging. 2018;38:911-92.

20. Cook GJ, Azad G, Padhani AR. Bone imaging in prostate cancer: the evolving roles of nuclear medicine and radiology. Clin Transl Imaging. 2016; 4(6):439-47.

21. Arvola $\mathrm{S}$, et al. Comparison of standardized uptake values between $(99 \mathrm{~m}) \mathrm{Tc}$ HDP SPECT/CT and (18) F-NaF PET/CT in bone metastases of breast and prostate cancer. EJNMMI Res. 2019;9(1):6.

22. Goyal P, et al. Elastofibroma dorsi. Proc (Bayl Univ Med Cent). 2017:30(3):340-2.

\section{Publisher's Note}

Springer Nature remains neutral with regard to jurisdictional claims in published maps and institutional affiliations.

Ready to submit your research? Choose BMC and benefit from:

- fast, convenient online submission

- thorough peer review by experienced researchers in your field

- rapid publication on acceptance

- support for research data, including large and complex data types

- gold Open Access which fosters wider collaboration and increased citations

- maximum visibility for your research: over $100 \mathrm{M}$ website views per year

At $\mathrm{BMC}$, research is always in progress.

Learn more biomedcentral.com/submissions 